\title{
The mating system and patterns of genetic variation in Banksia cuneata A. S. George (Proteaceae)
}

\author{
DAVID J. COATES \& RONALD E. S. SOKOLOWSKI \\ Western Australian Herbarium, Department of Conservation and Land Management, PO Box 104, Como, Western \\ Australia 6152
}

\begin{abstract}
The mating system and patterns of genetic variation were studied in the rare and geographically restricted species Banksia cuneata. Nine out of 20 allozyme loci analysed were polymorphic and six were considered suitable for estimating mating system parameters. Estimates of the outcrossing rate ranged from $t=0.67$ to $t=0.95$ and the effective selfing rate from $E=0.14$ to $E=0.25$, and showed significantly lower levels of outcrossing in two populations than reported for other Banksia species. This appeared to be due to increased biparental inbreeding associated with high plant density and reduced or altered pollinator activity associated with habitat disturbance. The six populations were clearly divided into two population groups $(\bar{D}$, between groups $=0.088)$ with significant gene flow estimated among populations within groups but not amoung groups. Although $B$. cuneata has an extremely restricted geographical range and is largely bird-pollinated, significant differentiation has occurred between some populations over relatively small geographical distances. The differentiation correlates with certain ecological features of the region and is a likely result of the dissected population structure and relatively small sized populations found in this species.
\end{abstract}

Keywords: Banksia cuneata, gene flow, genetic structure, mating system, population differentiation.

\section{Introduction}

The mating system is clearly a critical factor in determining patterns of genetic variation both within and among plant populations (Brown, 1989; Brown et al., 1989; Hamrick \& Godt, 1989). Polymorphic allozyme loci have proven to be extremely useful in developing quantitative estimates of plant mating system parameters (Brown, 1989; Hamrick, 1989) as demonstrated in a number of recent studies (Moran et al., 1989; Sampson et al., 1989; Warwick \& Thompson, 1989; Morgan \& Barrett, 1990; Watkins \& Levin, 1990) and have also provided a rapid and effective means for studying patterns of genetic variation in plant populations (see Soltis \& Soltis, 1989).

The mixed mating model (Fyfe \& Bailey, 1951; Brown et al., 1985) gives a robust and frequently used procedure for estimating mating system parameters. Recently, however, several new approaches have been developed (Brown, 1989) which enable further investigations of demographic and genetic causes of mating patterns. For example the effective selfing model (Ritland, 1984, 1986) calculates mating system para- meters in spatially structured populations and considers mating among relatives and selfing in the estimate of 'effective selfing'. However, as with the mixed mating model, it is limited by certain assumptions, in this case that the maternal plants are a random sample from the population producing pollen.

Estimates of outcrossing rates for species in the genus Banksia are typically very high (Scott, 1981; Carthew et al., 1988). The Banksia genus consists of largely bird and mammal pollinated species and apparently these pollinators move considerable distances and visit large numbers of plants when foraging (Carthew et al., 1988, Ayre \& Whelan, 1989). This suggests that pollen movement within populations may be extensive with little spatial genetic structure although even in wind-pollinated plants, where gene flow is expected to be higher (Hamrick \& Godt, 1989), genetic structure has been detected (Hamrick et al., 1989; Perry \& Knowles, 1990).

With high outcrossing rates and bird pollination one might expect most genetic variation to occur within rather than among Banksia populations (Brown, 1979; Hamrick \& Godt, 1989). However, many have quite 
dissected population structures and under these conditions both drift and selection may lead to localized or regional population differentiation even if birdmediated gene flow occurs.

Banksia cuneata is a rare species known from only six populations. It is characterized by a dissected population structure which has become even more fragmented following recent land clearing and habitat disturbance. It is closely related to $B$. ilicifolia and another rare species $B$. oligantha. All three species have a unique evolutionary status, with features intermediate between Banksia and a related genus Dryandra. Like B. ilicifolia (Lamont \& Collins, 1988), B. cuneata is considered to be largely bird pollinated. As in the case of many Proteaceae, flowers are protandrous and geitonogamous pollination is likely to be common (Ayre \& Whelan, 1989).

This study was carried out to investigate the mating system of $B$. cuneata and how it relates to population structure and patterns of genetic variation among populations. Because of its rarity and threatened status the effects of recently reduced population size and ecological disturbance on factors associated with the maintenance of genetic variation were also investigated. It was anticipated that information from this study would enable the development of appropriate conservation strategies for this species.

\section{Materials and methods}

\section{Population sampling and site descriptions}

Banksia cuneata is known from six populations covering a range of some $60 \mathrm{~km}$ in the central cereal growing areas of south west Australia (Fig. 1). Much of this area was cleared for agriculture some 50-60 years ago although around 7 per cent still exists as remnants, of various sizes, of the original native vegetation. Prior to land clearing $B$. cuneata would have had a dissected population structure restricted to the patches of deepyellow sandy soils which cover $10-15$ per cent of this area. Associated with these soils is a rich vegetation

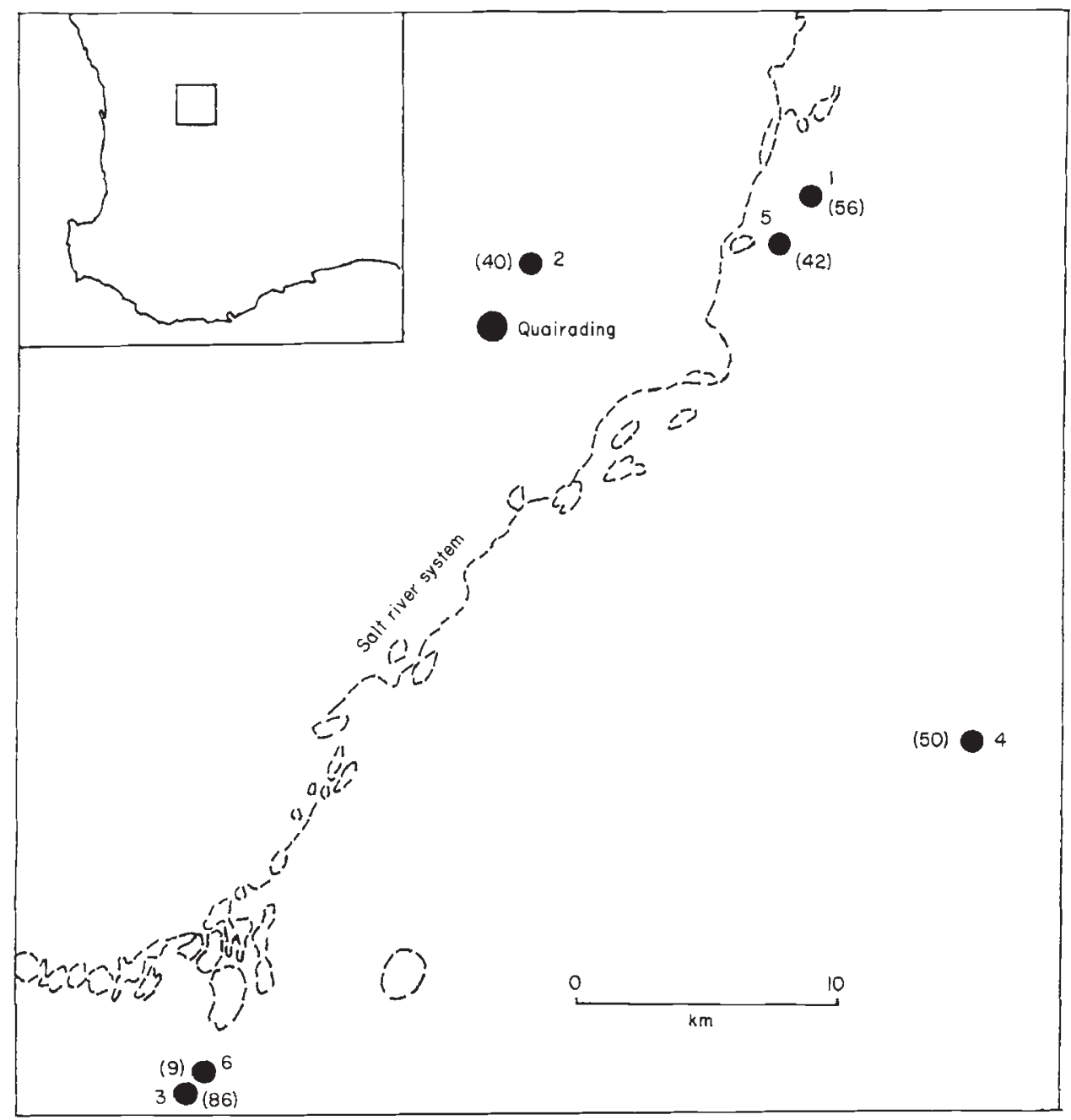

Fig. 1 Distribution of Banksia cuneata in south-west Australia and the number of plants (in brackets) per population. Apart from the roadside populations 1 and 6 , each population covers an area of between 1 and 3 hectares. 
system dominated by species of the families Proteacae, Myrtaceae and Leguminosae a number of which are important in maintaining the permanent populations of honeyeaters, the major pollinators of this species.

The six populations show marked differences in the extent of undisturbed native vegetation. Populations 2 and 5 have virtually undisturbed vegetation systems, populations 3 and 4 low levels of disturbance and populations 1 and 6 occur in highly disturbed roadside vegetation. All populations, apart from the road verge populations, cover an area of between one and three hectares and in populations 2, 4 and 5 mature plants are well spaced 2-5 $\mathrm{m}$ apart. In contrast, plants in population 1, and to a lesser extent population 2, are more densely packed and sometimes intertwined.

Seed material for allozyme electrophoresis was collected from all known populations (Fig. 1). More extensive collections were made from populations 1-4 to ensure sufficient numbers of maternal plants for mating system studies, however, because of relatively low numbers of plants within populations, and in some cases low seedset per plant, sampling was not always optimal. In most cases at least 10 follicles were collected per plant with an average of one seed per follicle.

\section{Electrophoresis}

Up to 20 seeds per plant were germinated on moistened filter paper with the number of seeds used depending upon sample size requirements for mating system studies. Seedlings with recently emerged radicals, minus the bulk of the large endosperm, provided the best material. Preparation of this material and the isozyme methods, using the Helena Laboratory cellulose acetate plate electrophoresis system, were as described previously (Coates, 1988).

Fourteen enzyme systems were assayed: aspartate aminotransferase (AAT, E.C.2.6.1.1), acid phosphatase (ACP, E.C.3.1.3.2), aconitase (AC, E.C.4.2.1.3) alcohol dehydrogenase $(\mathrm{ADH}$, E.C.1.1.1.1), esterase EST, E.C.3.1.1.-), glutamate dehydrogenase (GDH, E.C.1.4.1.2), isocitrate dehydrogenase (IDH, 1.1.1.42), leucine aminopeptidase (LAP, 3.4.17.1) malic enzyme (ME, E.C.1.1.1.40), malate dehydrogenase (MDH, 1.1.1.37), menadione reductase (MDR, E.C.1.6.99.22) phosphoglucose isomerase (PGI, E.C.5.3.1.9), phosphoglucomutase (PGM, E.C.2.7.5.1) shikimate dehydrogenase (SDH, E.C.1.1.1.25). In total 20 zones of activity were scored and each zone was assumed to represent a single locus. Nine polymorphic loci were detected and their genetic interpretation was based on segregation patterns of progeny arrays from open pollinated families. Of the polymorphic loci six had allele frequencies suitable for mating system estimation procedures.

\section{Mating system analysis}

Six loci Acp-1, Mdh-3, Pgi-1, Pgi-2, Pgm-1 and Pgm-2 were used to estimate mating system parameters. Estimates were based on 23 families with a mean of 14.6 progeny per family for population 1,21 families with a mean of 15.0 progeny per family for population 2,20 families with a mean of 14.9 progeny per family for population 3 , and 10 families with a mean of 17.2 progeny per family for population 4 . Estimates of the mixed mating model and the effective selfing model parameters and their variances were obtained using the computer programs developed by Ritland (Ritland \& Jain, 1981; Ritland 1984, 1986).

Estimates of maternal genotypes were inferred from progeny arrays by the method of Brown \& Allard (1970) and allele frequency differences between the maternal parents and pollen pool were investigated at the six loci within the four populations (Table 1). Based on the mixed-mating model, outcrossing rates $(\hat{t})$ and their standard errors were calculated for a single locus and as multilocus estimates using the joint maximumlikelihood methods of Ritland \& Jain (1981) and Ritland (1986).

In contrast to the mixed mating model the effective selfing model assumes equality of gene frequencies among pollen and ovules. This assumption appears to be upheld in at least populations 1 and 2 (Table 1). Because estimates are based on maternal parameters a sufficient number of maternal genotypes $(>24)$ are needed to avoid unreliable estimates. Population 4 was thus excluded from the analysis and it is apparent that family numbers from the other three populations are a little low. The program developed by Ritland estimates the total amount of apparent selfing at a single locus caused by either self fertilization or mating to relatives. This Ritland terms 'effective selfing'. Joint maximumlikelihood estimates of gene frequency, $F$, the inbreeding coefficient of parents, $s_{\mathrm{i}}$, the selfing rate of parents with fixed alleles and $s_{0}$, the selfing rate of parents with alleles not fixed, were calculated (see Ritland, 1986). These selfing rates were calculated as a minimum variance average of single-locus selfing rates averaged over all loci.

Three further estimates were subsequently obtained based on the effective selfing model (Ritland 1986; Ritland \& Ganders, 1985, 1987). $E$ 'the effective selfing rate', where

$E=F s_{\mathrm{i}}+(1-F) s_{0}$.

With no mating to non-self relatives $E$ equals the self 
Table 1 Allele frequencies for maternal parents and pollen gene pools for the four populations on which mating system studies were carried out

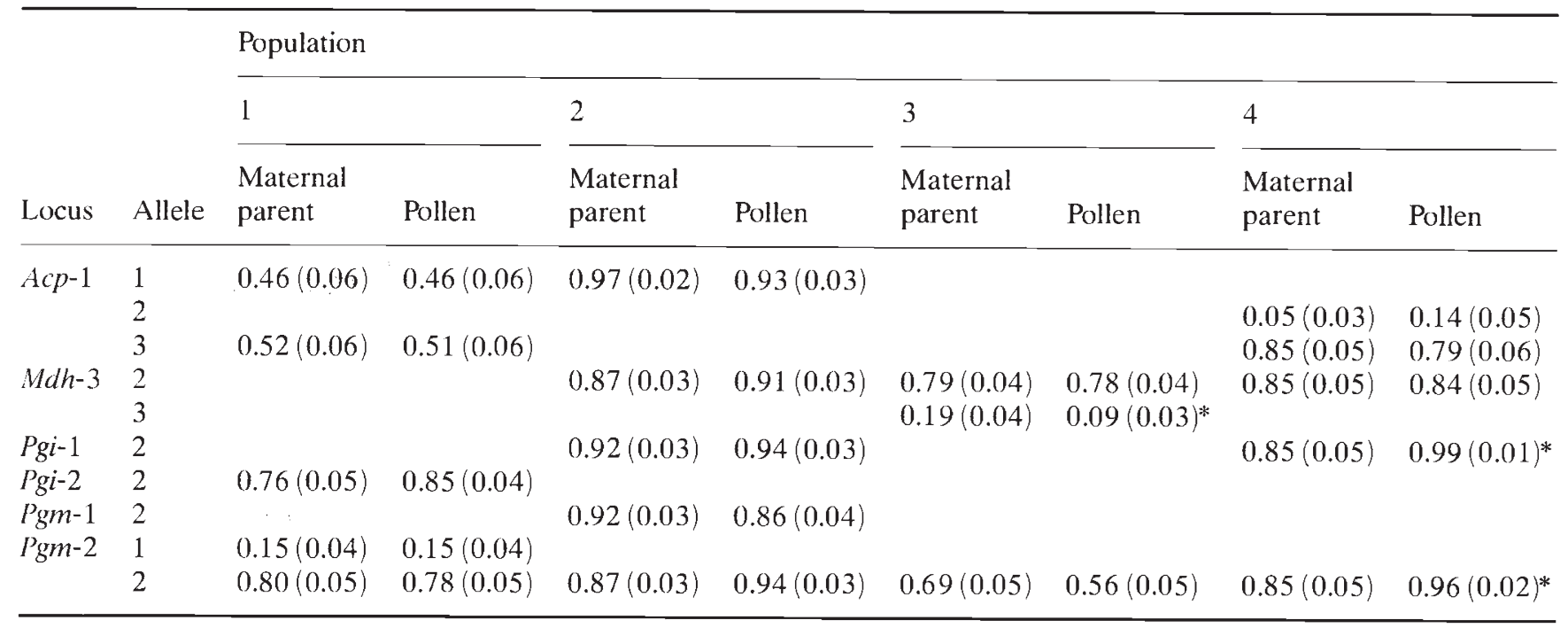

The most common allele for diallelic loci and the two most common alleles for triallec loci are given. Frequencies of greater than 0.99 at a locus for both maternal parents and pollen are not included. Standard errors are in parentheses. *Significant differences $(P>0.05)$ between maternal parents and pollen pool allele frequencies within populations.

fertilization rate. $D$ 'the inbreeding assortative selfing' or covariance of selfing with gene fixation, where

$D=F(1-f)\left(s_{\mathrm{i}}-s_{0}\right)$.

When $D=0$ the effective selfing and mixed mating models are mathematically the same but there may still be mating to relatives (Ritland 1986). The third estimate was $\Delta F$, the change in the fixation index from parents to progeny.

Estimates of outcrossing rate $(\hat{t})$ and the effective selfing rate $(E)$, based on different loci, may be correlated if those loci show linkage disequilibrium. To test for associations between loci the digenic disequilibrium coefficient $\Delta_{\mathrm{AB}}$ was calculated for all pairwise combinations of loci in the four populations (see Weir, 1990). If $\Delta_{\mathrm{AB}}$ is equal to zero the loci assort independently.

\section{Genetic variation within and among populations and gene flow}

Single locus diversity measures [the average number of alleles per locus $(A)$, percentage polymorphic loci $(P)$, observed heterozygosity $\left(H_{0}\right)$ and the expected panmictic heterozygosity $\left.\left(H_{\mathrm{e}}\right)\right]$ were calculated as described by Brown \& Weir (1983). The partitioning of genetic variation within and among populations, and among two distinct population groups, east (populations 1, 4 and 5) and west (populations 2, 3, and 6) was analysed by using measures proposed by Nei \& Chesser (1983) using the computer program GENESTAT (Whitkus, 1985). Nei's (1978) genetic distance $(\bar{D})$ was calculated for each pairwise combination of taxa using all 20 and a UPGMA phenogram constructed. Single locus diversity measures, Nei's $\bar{D}$ and the UPGMA phenogram, were determined using the computer program BIOSYS-1 (Swofford \& Selander, 1989).

Two indirect estimates of gene flow $(\mathrm{Nm})$ were calculated between populations and between the two population groups. The first was based on the relationship $F_{\mathrm{ST}}=1 /[4 \mathrm{Nm}+1]$ (Wright, 1951). The second is based on the frequency distributions of private alleles $p(l)$ (alleles found in only a single population) using the relationship:

$$
\log _{10}[p(l)]=a \log _{10}(N m)+b
$$

where $a$ and $b$ depend on the number of individuals sampled from each population (Slatkin, 1985; Barton \& Slatkin, 1986; Slatkin \& Barton, 1989).

\section{Results}

\section{Parent and pollen allele frequencies}

Allele frequencies for the maternal parents and pollen pool at loci used in the mating system studies are presented in Table 1. Where allele frequencies are not indicated the frequency of the common allele was $>0.98$ in the maternal parents. Comparisons between populations 1-4 indicate clear differences in allele frequencies between all populations and all six loci appear to be associated in this differentiation. In particular $A c p-1$ differentiated between populations 2 and 3 , and 
1 and 4 with allele 3 occurring at a frequency of $<0.04$ in populations 2 and 3 while at a frequency $>0.50$ in populations 1 and 4.

Significant differences between allele frequencies in the maternal parents and pollen pool loci were detected in only 3 out of 19 comparisons covering all four populations (Table 1). In populations 1 and 2 there were no significant differences, in populations 3 one significant difference at the locus $M d h-3$ and in population 4 two, at the loci Pgi-1 and Pgm-2. These data indicate that, with the possible exception of population 4 , the maternal parents contribute equally to the pollen pool at most loci. This is clearly important when considering the assumptions of the effective selfing model.

\section{Outcrossing}

Single locus and multilocus estimates of outcrossing rates, based on the mixed mating model, are given in Table 2 . In populations 1 and 3 all estimates differed significantly from random mating $(\hat{t}=1)$. In population 2 only one estimate, for the $M d h-3$ locus, indicated a significant deviation from random mating while in population 4 all estimates indicated random outcrossing. The mean single locus and multilocus estimates of $\hat{t}$ were not significantly different from each other which suggests that there may be little biparental inbreeding due to sub-population structure in the four populations studied.

\section{Effective selfing and population structure}

Gene fixation and mating system estimates, based on the 'effective selfing' model, are presented in Table 3 . There is considerable heterogeneity in these estimates between the three populations studied. The fixation indices ranged from no significant gene fixation in the parents in populations 2 and 3 to significant fixation in population 1. Effective selfing rates $(E)$ ranged from
0.25 in population 3 to 0.14 in population 2 . The covariance of selfing with parental gene fixation $\langle D\rangle$ was significantly greater than zero in population 1 although it was positive in population 3 . A significant increase in gene fixation from parents to progeny $\Delta F$ was observed in population 2 and 3 but not in population 1 .

\section{Linkage disequilibrium}

The estimates of composite linkage disequilibrium $\Delta_{\mathrm{AB}}$ are given in Table 4. Significant disequilibrium was detected between some combinations of loci in populations 1, 3 and 4. In population 1, in particular, three of the six combinations of loci showed significant disequilibrium. The only significant occurrence of disequilibrium consistent between populations was for the Pgm-2/Pgi-1 combination for populations 2 and 4. Generally these data indicated that little association between loci was present and, with the possible exception of population 1, single locus estimates of outcrossing and effective selfing were likely to be independent.

\section{Patterns of genetic variation and gene flow}

Values for the average number of alleles per locus $(A)$, percentage polymorphic loci $(P)$, average observed heterozygosity $\left(H_{0}\right)$ and expected panmictic heterozygosity $\left(H_{\mathrm{e}}\right)$ are presented in Table 5. Population 1 has the highest values for $A(1.6), P(45.0)$, and $H_{\mathrm{e}}(0.10)$ while population 2 has the lowest values for $A(1.3)$, $h_{0}(0.04)$ and $H_{\mathrm{e}}(0.04)$. With the exception of population $6, H_{0}$ is marginally less than or equal to $H_{\mathrm{e}}$ and in population 1 the difference is the greatest, a result expected given the mating system studies. If one considers the percentage of polymorphic loci, population 6 is unusual because the small population (Fig. 1) has on average nearly four times the heterozygosity per locus when compared with population 1 .

Table 2 Single locus and multilocus estimates of outcrossing $(\hat{t})$ based on the mixed mating model and calculated from progeny genotype arrays for four populations

\begin{tabular}{llllllllll}
\hline & \multicolumn{2}{l}{ Locus } & & & & & & \\
\cline { 2 - 6 } Population & Acp-1 & Pgm-1 & Pgm-2 & Pgi-1 & Pgi-2 & Mdh-3 & Mean & Multilocus \\
\hline 1 & $0.61(0.06)^{*}$ & & $0.84(0.08)^{*}$ & & $0.50(0.08)^{*}$ & & $0.65(0.04)^{*}$ & $0.67(0.04)^{*}$ \\
2 & $0.93(0.14)$ & $1.16(0.10)$ & $1.07(0.11)$ & $0.84(0.14)$ & & $0.70(0.12)^{*}$ & $0.94(0.06)$ & $0.95(0.05)$ \\
3 & $1.12(0.09)$ & $0.65(0.06)^{*}$ & & \multirow{2}{*}{$0.76(0.18)$} & & $0.78(0.08)^{*}$ & $0.72(0.05)^{*}$ & $0.76(0.05)$ \\
4 & & & $0.89(0.13)$ & $0.92(0.08)$ & $0.88(0.07)$ \\
\hline
\end{tabular}

*Significantly less than $1(P<0.05)$. 
Table 3 Gene fixation and mating system estimates for three populations based on the effective selfing model. $F_{\mathrm{m}}$ is the fixation index of parents, $E$ is the effective selfing rate, $D$ is the covariance of effective selfing with gene fixation, and $\Delta F$ is the change in $F$ from parents to progeny

\begin{tabular}{lllll}
\hline Population & $F_{\mathrm{m}}$ & $E$ & $D$ & $\Delta F$ \\
\cline { 2 - 3 } 1 & $0.18(0.07)^{*}$ & $0.23(0.05)^{*}$ & $0.10(0.03)^{*}$ & $0.01(0.05)$ \\
2 & $0.00(0.06)$ & $0.14(0.06)$ & $0.00(0.05)$ & $0.07(0.02)^{*}$ \\
3 & $0.02(0.04)$ & $0.25(0.06)^{*}$ & $0.02(0.03)$ & $0.11(0.03)^{*}$ \\
\hline
\end{tabular}

*Significantly different from $0(P<0.05)$.

Table 4 Estimates of composite linkage disequilibrium $\Delta_{\mathrm{AB}}$ between allozyme loci in progeny from the four populations on which mating system studies were carried out

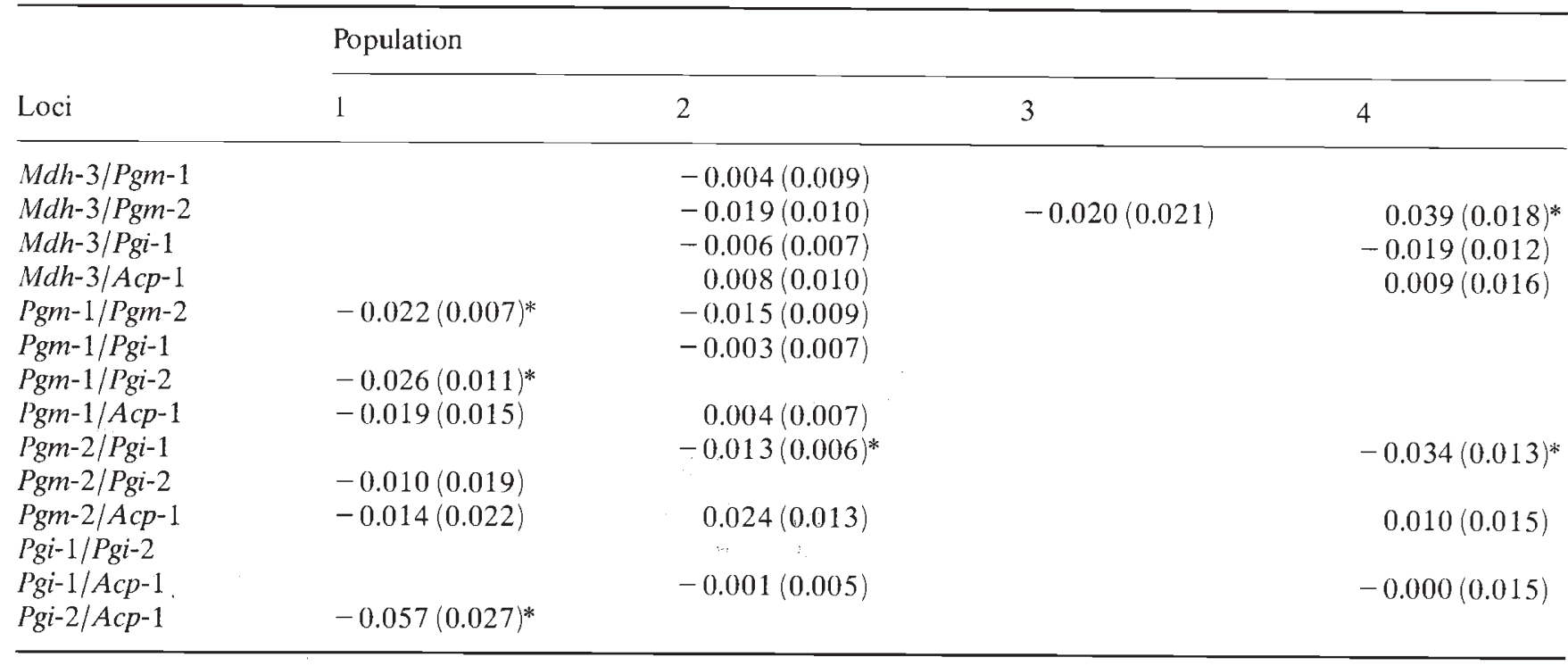

*Significantly different from $0(P<0.05)$.

Table 5 Single locus diversity measures for all populations of Banksia cuneata

\begin{tabular}{lrllll}
\hline Population & \multicolumn{1}{l}{$N_{\mathrm{L}}$} & \multicolumn{1}{l}{$A$} & $P$ & \multicolumn{1}{l}{$H_{0}$} & \multicolumn{1}{l}{$H_{\mathrm{c}}$} \\
\hline 1 & 104.2 & 1.6 & 45.0 & $0.07(0.02)$ & $0.10(0.04)$ \\
2 & 68.3 & 1.3 & 25.0 & $0.04(0.02)$ & $0.04(0.02)$ \\
3 & 88.2 & 1.4 & 20.0 & $0.05(0.03)$ & $0.06(0.03)$ \\
4 & 51.3 & 1.5 & 35.0 & $0.06(0.02)$ & $0.08(0.03)$ \\
5 & 15.0 & 1.4 & 25.0 & $0.06(0.03)$ & $0.08(0.04)$ \\
6 & 9.0 & 1.4 & 25.0 & $0.11(0.05)$ & $0.09(0.04)$ \\
\hline
\end{tabular}

$N_{\mathrm{L}}=$ mean sample size per locus; $A=$ mean number of alleles per locus; $P=\%$ polymorphic loci; $H_{0}=$ observed

heterozygosity; $H_{\mathrm{e}}=$ expected panmictic heterozygosity.

Nei's diversity measures for studying the partitioning of genetic variation within and among populations are presented in Table 6. Two distinct population groups were apparent from the allele frequency data and the UPGMA based on Nei's $\bar{D}$ (Fig. 2). The partitioning of genetic variation was thus based on the east and west population groups and then all populations. The easterly populations $(1,4$ and 5$)$ appear to be a relatively homogeneous group, as indicated by the quite low level of genetic differentiation between populations $\left\langle G_{\mathrm{ST}}=0.083\right)$. The westerly populations are somewhat less homogeneous $\left(G_{\mathrm{ST}}=0.145\right)$ which might be expected given the greater distance between populations (Fig. 1). If we consider all populations equally there is a dramatic increase in the level of differentiation between populations $\left(G_{\mathrm{ST}}=0.227\right)$. This clearly supports the notion of two distinct population groups.

Overall the total genetic diversity $\left(H_{\mathrm{T}}\right)$ is substantially lower than the average for plant taxa as are $H_{\mathrm{S}}$ and $G_{\mathrm{ST}}$ (Hamrick \& Godt, 1989). This also applies to $H_{\mathrm{T}}$ and $H_{\mathrm{S}}$ when considering the mating system and the geographic range of $B$. cuneata. 
Table 6 Gene diversity statistics and gene flow estimates for the east and west population groups

\begin{tabular}{lllllll}
\hline & & & & & \multicolumn{2}{c}{$N m$} \\
\cline { 5 - 7 } Population & $H_{\mathrm{T}}$ & $H_{\mathrm{S}}$ & $G_{\mathrm{ST}}$ & $p(1)$ & Slatkin & Wright \\
\hline East & 0.211 & 0.193 & 0.083 & 0.025 & 4.56 & 2.76 \\
West & 0.163 & 0.140 & 0.145 & 0.081 & 0.67 & 1.47 \\
Total & 0.216 & 0.167 & 0.227 & 0.080 & 0.68 & 0.85 \\
\hline
\end{tabular}

$H_{\mathrm{I}}=$ total genetic diversity; $H_{\mathrm{S}}=$ genetic diversity within populations;

$G_{\mathrm{ST}}=$ proportion of the total genetic diversity among populations; $p(1)=$ frequency of private alleles; $\mathrm{Nm}=$ estimate of gene flow.
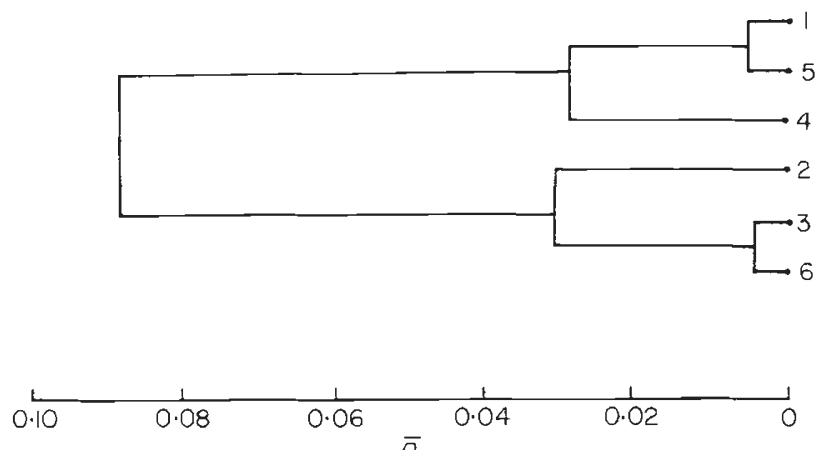

Fig. 2 UPGMA clustering of Banksia cuneata populations based on Nei's genetic distance $(\bar{D})$.

Extensive gene flow $(\mathrm{Nm})$ is apparent among the easterly populations 1,4 and 5 (Table 6 ) at levels considerably higher than the average for outcrossed wind pollinated taxa (Hamrick, 1989). In contrast estimates of gene flow among the westerly populations are noticeably lower no doubt due to the geographical isolation of population 2. Overall the estimates of gene flow are comparable to estimates for other plant taxa with similar mating systems (Hamrick, 1989) although this does not take into account the presence of the two distinct population groups.

\section{Discussion}

\section{The mating system}

Banksia species studied to date are considered to be both bird and mammal pollinated and have outcrossing rates among the highest recorded for plants (Scott, 1981; Carthew et al., 1988). Although high outcrossing rates appear to be typical of some populations of $B$. cuneata, the data from this study indicate substantial differences in the mating system between populations. Populations 1 and 3 show a significant reduction in the estimated level of outcrossing and significant levels of effective selfing when compared to populations 2 and 4 (Tables 2 and 3).

Variation in outcrossing rates between populations appears to be a common phenomenon in mixed mating species (Schoen, 1982). Although Lande \& Schemske (1985) predict that equilibrium populations should be characterized by predominant selfing or predominant outcrossing they point out that at least in some species environmental and demographic factors may maintain non-equilibrium conditions characteristic of species with variable levels of outcrossing. This is perhaps not unexpected given the range of ecological and genetic factors which could affect the mating system and which may vary between populations (see Brown et al., 1989). These factors may include mode of pollination, pollinator availability, floral structure, population size and density and the genetic control of self incompatibility and post zygotic effects.

In $B$. cuneata field observations suggest that both plant density and population structure, and pollinator availability and activity will have a significant influence on interpopulation variation in the mating system. If we first consider plant density it seems likely that high density populations will be characterized by greater relatedness between neighbouring plants, higher levels of crossing between relatives and a high degree of genetic structure (see Watkins \& Levin, 1990).

The influence of population structure on the mating system has been the subject of a number of recent studies particularly in relationship to the estimation of outcrossing or selfing rates and violations of the mixed mating model (Ritland, 1986; Brown, 1989). It has been shown that single-locus estimates of outcrossing, based on the mixed mating model, are biased downwards because they include both true selfing and biparental inbreeding whereas multilocus estimates are, in theory, less affected by consanguineous matings and are considered to give a better estimate of true self- 
ing. In this study, however, comparisons of multilocus estimates with the mean single locus estimates gave little indication of any biparental inbreeding.

In structured populations, where outcrossing is nonrandom, it has been proposed that the mating system may be more generally described by components of the effective selfing model which extends the mixed mating model to non-random mating (Ritland, 1984, 1986). If we look further at the consequences of population structure in terms of the effective selfing model, we need to consider the fixation index of parents $\left(F_{\mathrm{m}}\right)$ and the two mating system parameters average effective selfing rate $(E)$ and the covariation of effective selfing with parental gene fixation $(D)$ (Ritland \& Ganders, 1987).

Although positive in all three populations studied, significant levels of $F_{\mathrm{m}}$ were detected only in population 1. In this population significant numbers of progeny resulting from self-fertilization and/or biparental inbreeding appear to have survived to maturity. In contrast, in populations 2 and 3 gene fixation increased significantly from parents to offspring (Table 3 ). This suggests that in populations 2 and 3, but not in population 1 , selection favouring heterozygotes, or outcrossed individuals, has occurred during the life cycle from seedlings to adults. It is not clear why heterozygote selection is apparently absent from population 1 although it is possible that selection regimes may have been substantially altered in this now highly disturbed population. Increased fitness associated with increased heterozygosity has been clearly demonstrated in a number of plant species (Ledig, 1986) and it is significant to note that selection favouring outcrossed zygotes operating between fertilization and the point at which seedlings are assayed is also likely to occur in Banksia (Ayres \& Whelan, 1989), and indeed in many other plant groups (see Ledig, 1986; Weins et al., 1987; Burbidge \& James, 1991).

In the two species where the effective selfing model has been used to study the mating system, Bidens menzeisii (Ritland \& Ganders, 1985) and Mimulus guttatus (Ritland \& Ganders, 1987), the covariance of selfing with parental gene fixation $(D)$ was positive within most populations and could be attributed to sub-population structure and mating between relatives. It was concluded that this covariance was common in inbreeding populations. Unlike $M$. guttatus and $M$. bidens, $B$. cuneata is a largely bird-pollinated woody shrub or small tree and is relatively long lived (30-50 years). Only in population 1 was $D$ significant, which suggests that the increased inbreeding observed in this population was at least partly due to increased mating between relatives. This can be attributed to subpopulation structure in association with the high plant density previously observed in this population (B. B.
Lamont unpublished data). Similarly the increased inbreeding observed in population 3 is also associated with increased plant density, although in this population density is somewhat intermediate between population 1 and the low density observed in population 2. Similar density-dependent effects occur in the insect-pollinated species Phlox drummondii (Watkins \& Levin, 1990) and Helianthus annuus (Ellestrand et al., 1978) where selfing rates are higher in more dense populations presumably due to the closer proximity of related plants.

As mentioned previously, pollinator availability and activity are also likely to have a significant influence on mating system differences between populations, particularly in a largely bird-pollinated species such as $B$. cuneata. Schemske \& Lande (1985) indicate that in some insect-pollinated plants the extremely high levels of interpopulation variation in outcrossing rates can be largely attributed to pollinator behaviour. Population disturbance, which in the case of $B$. cuneata results in the loss of understorey species and thus a food resource for the honeyeaters, is likely to have a dramatic effect on pollinator behaviour. The increased levels of inbreeding observed in the highly disturbed population 1 is probably in some part due to a reduced and transient pollinator activity. In contrast the higher levels of outcrossing found in population 2 can be partly attributed to increased pollinator activity associated with a more permanent population of honeyeaters. This relationship between habitat disturbance, pollinator activity and inbreeding is also apparent in population 3 where a moderate level of habitat disturbance is again associated with reduced outcrossing (Table 2).

\section{Population differentiation and gene flow}

The dissected population structure and extremely restricted range of $B$. cuneata would be expected to have a major influence on the patterns of genetic variation within and among populations (Karron, 1987; Hamrick \& Godt, 1989). Relative to other plant taxa (Hamrick \& Godt, 1989) B. cuneata has low levels of allozyme diversity (Table 5). This is even more apparent when considering species with similar mating systems or restricted geographical ranges.

As $B$. cuneata is outcrossing and largely birdpollinated, initial expectations would be little differentiation between populations. Overall population differentiation in B. cuneata $\left(G_{\mathrm{ST}}=0.227\right)$ (Table 6) is somewhat higher than other animal-pollinated outcrossing taxa $\left(G_{\mathrm{ST}}=0.187\right)$ although gene flow estimates $\left(N_{\mathrm{m}}=0.67\right.$ and 1.47$)$ are similar (Hamrick, 1989). It is apparent, however, that B. cuneata consists of two distinct population groups (Fig. 2) which corre- 
lates with the dissection of its range by a major salt river system (Fig. 1). The ecosystem associated with this ephemeral salt river would provide no suitable habitat for either B. cuneata or its pollinators.

The effectiveness of the salt river system as a barrier is reflected in the low level of differentiation observed between populations 1,5 and the isolated population 4 $\left(G_{\mathrm{ST}}\right.$ east $\left.=0.083\right)$ when compared to that between populations 1,5 and the geographically much closer population 2 (Fig. 2). The westerly group of populations (2, 3 and 6) form a far more heterogeneous group $\left[G_{\mathrm{ST}}\right.$ west $=0.145, N_{\mathrm{m}}($ Slatkin, 1985) $=0.67]$ although they still show closer affinity with each other than to any of the eastern populations (Fig. 2, Table 6). This is unexpected given the substantial isolation of population 2. In B. cuneata, in comparison with some other plant species with a dissected population structure (Moran \& Hopper, 1983; Wendal \& Parkes, 1985; Sampson et al., 1988), geographical proximity does not always coincide with high estimated levels of gene flow. Even over an extremely restricted geographical range significant differentiation has occurred between some populations apparently in association with certain ecogeographical features of the area.

Alternatively within-population groups estimates of gene flow, particularly in the eastern population group, are relatively high for an animal-pollinated species (Hamrick, 1989). This suggests that bird-mediated gene flow within population systems may be very effective in maintaining genetic cohesion between populations and allelic diversity within populations. Similarly in E. rhodantha, another bird-pollinated species with a dissected population structure, a high level of gene flow was found between populations and was considered part of a genetic system which maintained high allozyme diversity within populations (Sampson et al., 1989).

Given the limited management resources available there are certain strategies which could be pursued to ensure the adequate in situ conservation of genetic resources in $B$. cuneata. One approach involves the selection of priority populations for genetic conservation which could be based on the presence of rare but locally common alleles (Brown, 1978), genetic differentiation between populations and the level of genetic diversity within populations (Hopper \& Coates, 1990). Thus at least one population from each population group would need to be selected and based on single locus diversity measures (Table 5 ) population 1 would have a high priority for conservation even though mating system studies indicate it has high levels of inbreeding (Tables 2 and 3 ).

In conclusion the fragmented populations of $B$. cuneata show significant interpopulation differences in the level of inbreeding and significant differentiation over a restricted geographical range. Although this species is largely bird-pollinated, limited gene flow between some adjacent populations, apparently due to habitat barriers to pollinator movement, has resulted in two divergent population groups. In contrast gene flow within population groups is relatively high and is likely to be important in maintaining genetic diversity in the small isolated populations found in this dissected population system.

\section{Acknowledgements}

We would like to thank Dr Tony Brown and Dr Steven Hopper for reviewing the manuscript, Steven van Leeuwen and Leon Sylvester for assistance in the collection of seed material and Steven Carstairs for his expert assistance in allozyme electrophoretic techniques.

\section{References}

AYRES, D. J. AND WHELAN, R. J. 1989. Factors controlliing fruit set in hermaphroditic plants: studies with the Australian Proteaceae. Trends Ecol. Evol., 4, 267-272.

BARTON, N. H. AND SLATKIN, M. 1986. A quasi-equilibrium theory of the distribution of rare alleles in a subdivided population. Heredity, 56, 409-415.

BROWN, A. H. D. 1979. Enzyme polymorphisms in plant populations Theor. Pop. Biol., 15, 1-42.

BROWN, A. H. D. 1989. Genetic characterization of plant mating systems. In: Brown, A. H. D., Clegg, M. T., Kahler, A. L. and Weir, B. S. (eds) Plant Population Genetics, Breeding, and Genetic Resources, Sinauer Associates, Sunderland, pp. 145-162.

BROWN, A. H. D. AND ALLARD, R. W. 1970. Estimation of mating the system in open pollinated maize populations using isozyme polymorphisms. Genetics, 66, 133-145.

BROWN, A. H. D., BARRETT, S. C. H. AND MORAN, G. F. 1985. Mating system estimation in forest trees: models, methods and meanings. In: Gregorius, H. R. (ed) Population Genetics of Forestry, Lecture Notes in Biomathematics, vol. 60, Springer-Verlag, Berlin, pp. 32-49.

BROWN, A. H. D., BURDON, J. J. AND JAROsz, A. M. 1989. Isozyme analysis of plant mating systems. In: Soltis, D. E. and Soltis, P. S. (eds) Isozymes in Plant Biology, Dioscorides Press, Portland, pp. 73-86.

BROWN, A. H. D. AND WEIR, B. A. 1983. Measuring genetic variability in plant populations. In: Tanksley, S. D. and Orton, T. J. (eds) Isozymes in Plant Genetics and Breeding, Elsevier, Amsterdam, pp. 219-239.

BURbidge, A. H. AND JAMES, S. H. 1991. Postzygotic seed abortion in the genetic system of Stylidium (Angiospermae:Stylidiacceae) J. Hered., 82, 319-328. 
CARTHEW, S. M., AYRE, D. J. AND WHELAN, R. J. 1988. High levels of outcrossing in populations of Banksia spinulosa $\mathrm{R} . \mathrm{Br}$. and Banksia paludosa Smith. Aust. J. Bot., 36, 217-223.

COATES, D. J. 1988. Genetic diversity and population genetic structure in the rare Chittering grass wattle Acacia anomala (Court) Aust. J. Bot., 36, 273-286.

ElLESTRAND, N. C., TORRES, A. M. AND LEVIN, D. A. 1978. Density and the rate of apparent outcrossing in Helianthus annuus (Asteraceae) Sys. Bot., 3, 403-407.

FYFE, J. L. AND BAILEY, N. T. J. 1951. Plant breeding studies in leguminous forage crops. 1. Natural cross breeding in winter beans. J. Agric. Sci., 41, 371-378.

HAMRICK, J. L. 1989. Isozymes and the analysis of genetic structure in plant populations. In: Soltis, D. E. and Soltis, P. S. (eds) Isozymes in Plant Biology, Dioscorides Press, Portland, pp. 73-86.

HAMRICK, J. L., BLANTON, H. M. AND HAMRICK, K. L. 1989. Genetic structure of geographically marginal populations of ponderosa pine. Am. J. Bot, 76, 1559-1568.

HAMRICK, J. L. AND GODT, M. J. 1989. Allozyme diversity in plant species. In: Brown, A. H. D., Clegg, M. T., Kahler, A. L. and Weir, B. S. (eds) Plant Population Genetics, Breeding, and Genetic Resources, Sinauer Associates, Sunderland, pp. 43-63.

HOPPER, S. D. AND COATES, D. J. 1990. Conservation of genetic resources in Australia's flora and fauna. Proc. Ecol. Soc. Aust., 16., 567-577.

KARRON, D. 1987. A comparison of levels of genetic polymorphism and self-compatibility in geographically restricted and widespread plant congeners. Evol. Ecol., 1, 45-58.

LAMONT, B. B. AND COLLINS, B. G. 1988. Flower colour change in Banksia ilicifolia: a signal for pollinators Aust. J. Ecol., 13, 129-135.

LANDE, R. AND SCHEMSKE, D. W. 1985. The evolution of selffertilization and inbreeding. 1. Genetic Models. Evolution, 39, 24-40.

LEDIG, F. T. 1986. Heterozygosity, heterosis, and fitness in outbreeding plants. In: Soule, M. E. (ed.) Conservation Biology, the Science of Scarcity and Diversity, Sinauer Associates, Sunderland, pp. 77-104.

MORAN, G. F. AND HOPPER, S. D. 1983. Genetic diversity and insular population structure of the rare granite rock species Eucalyptus caesia Benth. Aust. J. Bot., 31, 161-172.

MORAN, G. F., MUONA, O. AND BELL, J. C. 1989. Breeding systems and genetic diversity in Acacia auriculiformis and $A$. crassicarpa. Biotropica, 21, 250-256.

MORGAN, M. T. AND BARRETT, S. C. H. 1990. Outcrossing rates and correlated mating within a population of Eichornia paniculata (Pontederiaceae). Heredity, 64, 271-280.

NEI, M. 1978. Estimation of linkage heterozygosity and genetic distance from a small number of individuals. Genetics, 89, 583-590.

NEI, M. AND CHESSER, R. K. 1983. Estimation of fixation indices and gene diversities Ann. Hum. Genet., 47, 253-259.

PERRY, D. J. AND KNOWLES, P. 1990. Spatial genetic structure within three sugar maple (Acer saccharum Marsh) stands. Heredity, 66, 137-142.
RITLAND, K. 1984. The effective proportion of self fertilization with consanguinous matings in inbred populations. Genetics, 106, 139-152.

RITLAND, K. 1986. Joint maximum likelihood estimation of genetic and mating structure using open pollinated progenies. Biometrics, 42, 25-43.

RITLAND, K. AND GANDERS, F. R. 1985. Variation in the mating system of Bidens menziesii (Asteraceae) in relation to population substructure. Heredity, 55, 235-244.

RITLAND, K. AND GANDERS, F. R. 1987. Covariation of selfing rates and parental gene fixation indices within populations of Mimulus guttatus. Evolution, 41, 760-771.

RITLAND, K. AND JAIN, s. 1981. A model for the estimation of outcrossing rate and gene frequencies using $n$ independent loci. Heredity, 47, 35-52.

SAMPSON, J. F., HOPPER, S. D. AND JAMES, S. H. 1988. Genetic diversity and the conservation of Eucalyptus crucis Maiden. Aust. J, Bot., 36, 447-460.

SAMPSON, J. F., HOPPER, S. D. AND JAMES, S. H. 1989. The mating system and population genetic structure in a bird pollinated mallee, Eucalyptus rhodantha. Heredity, 63, 383-393.

SCHEMSKE, D. W. AND LANDE, R. 1985. The evolution of selffertilization and inbreeding depression in plants. II. Empirical observations. Evolution, 39, 41-52.

SCHOEN, D. J. 1982. The breeding system of Gilia achilleifolia: variation in floral characteristics and outcrossing rate. Evolution, 36, 596-613.

scoTt, J. K. 1981. Estimation of the outcrossing rate for Banksia attenuata R. Br. and Banksia menziesii R. Br. (Proteaceae). Aust. J. Bot. 28, 53-59.

SLATKIN, M. 1985. Rare alleles as indicators of gene flow. Evolution, 39, 53-65.

SLATKIN, M. AND BARTON, N. H. 1989. A comparison of three indirect methods for estimating average levels of gene flow. Evolution, 43, 1349-1368.

SOltis, D. E. AND SolTis, P. S. (eds) 1989. Isozymes in Plant Biology. Advances in Plant Sciences Vol. 4. Dioscorides Press, Portland, Oregon.

SWOFFORD, D. L. AND SELANDER, R. K. 1981. A computer program for the analysis of allelic variation in genetics. $J$. Hered., 72, 281-283.

WATKINS, L. AND LEVIN, D. A. 1990. Outcrossing rates as related to plant density in Phlox drummondii. Heredity, 65, $81-90$

WARWICK, S. I. AND THOMPSON, B. K. 1989. The mating system in sympatric populations of Carduus nutans, $C$. acanthoides and their hybrid swarms. Heredity, 63, 329-338.

weIr, B. s. 1990. Genetic Data Analysis. Sinauer Associates, Sunderland, Massachusetts.

WENDEL, J. F. AND PARKES, C. R. 1985. Genetic diversity and population structure in Camellia japonica L. (Theaceae). Am. J. Bot. 72, 52-65.

WIENS, D., CALVIN, C., WILSON, C. A. FRANK, D. AND LEAVEY, S. 1987. Reproductive success, spontaneous embryo abortion, and genetic load in flowering plants. Oecologia, 71, 501-509.

WHITKUS, R. 1985. FORTRAN program for computing genetic statistics from allelic frequency data. J. Hered., 76, 142.

WRIGHT, S. 1951. The genetical structure of populations. Ann. Eugen., 15, 323-354. 